\title{
SUPER ABSORBENT POLYMERS IN ENVIRONMENTAL REMEDIATION
}

\author{
R. DHODAPKAR* \\ P. BORDE \\ T. NANDY
}

Received: 09/09/08

Accepted: 16/12/08
National Environmental Engineering Research Institute, Nagpur Council of Scientific and Industrial Research, India

\begin{abstract}
Laboratory studies reported earlier, have shown very promising results in the selective removal of dyes from aqueous solutions by a commercially available (super absorbent polymer) SAP, Jalshakti ${ }^{\circledR}$ (JS). JS is mesoporous in nature and is a potential adsorbent for the basic dyes studied. This paper presents the adsorption and kinetic studies for the Methylene blue dye (MB) in a batch mode. The equilibrium adsorption capacity increases from 138.9 to $1428.6 \mathrm{mgg}^{-1}$ as the initial concentration of MB increases from $100-1000 \mathrm{mg} \mathrm{l}^{-1}$. The maximum adsorption capacity obtained is $1200 \mathrm{mgg}^{-1}$ which is more than the adsorbents reported in literature. The $K_{f}$ value is $165.3 \mathrm{mg}^{1-(1 / n)} \mathrm{g}^{-1} \mathrm{~L}^{1 / \mathrm{n}}$. The slope $1 / \mathrm{n}$, ranging between 0 and 1 , is indicative of the relative energy distribution on the adsorbent surface (or surface heterogeneity) The kinetics of the adsorption process suggests that the pseudo second order model is predominant. The pore diffusion kinetics as described by intraparticle diffusion model also controls the adsorption process but is not the only rate limiting mechanism.
\end{abstract}

KEYWORDS: Super absorbent polymers, Jalshakti, adsorption kinetics, Methylene Blue dye, intraparticle diffusion.

\section{INTRODUCTION}

Super absorbent polymers (SAPs) are compounds that absorb water and swell into many times their original size and weight. They are lightly cross-linked networks of hydrophilic polymer chains. The network can swell in water and hold a large amount of water while maintaining the physical dimension structure (Buchholz and Graham, 1997; Mahdavinia et al., 2004). It was known that commercially used water-absorbent polymeric materials employed are partial neutralization products of cross-linked polyacrylic acids, partial hydrolysis products of starch-acrylonitrile copolymers and starch-acrylic acid graft copolymers. At present, the material's biodegradability is an important focus of the research in this field because of the renewed attention towards environmental protection issues (Lenzi et al., 2003). The half life is in general in the range 5 - 7 years, and they degrade into ammonium, carbon dioxide and water.

SAPs are widely used in personal hygiene products. Recent research is focused in other application areas of SAPs, viz., biosensing, soft actuators/valves, catalysis, concentration of viruses, vitamin, bovine serum albumin and controlled drug delivery. SAPs or hydrogels have been also studied for the concentration of macromolecules (Cussler et al., 1984; Gehrke et al., 1986; Freitas and Cussler, 1987; Badiger et al., 1992; Vasheghani-Farahani et al., 1992). SAPs are used in soil to create a water reserve, near the rhizosphere zone (roots) and benefit agriculture.

The surface substitution of SAPs by cationic and anionic groups results in transformation of SAPs into selective and effective sorbents (Grifin 1994; Scott and Gilead 1995; Bastioli,1995). The combination of super absorbent polymer (SAP) and fertilizers, i.e., incorporating fertilizers and SAP in a single formulation named as water-absorbent slow release fertilizer is a trend 
in international fertilizer research, (Mikkelsen 1994, 1995; He et al., 2006; Ye et al., 2000; Zhou 2003; Smith and Harrison 1991; Pill and Watts 1983; Du 2002; Abraham and Pillai 1996; He and Zhang 2005; Zhan et al., 2004; Guo et al., 2005; Wang et al., 2005; Li, 2003; Karadag et al., 2000).

Compared with traditional adsorbents such as the silica gels, aluminas and the activated carbons (Kunin, 1976), the polymeric adsorbents are viewed as a more attractive alternative for the controllable pore structures and surface characteristics, for example, the commercially available Amberlite XAD-4 resin was reported as an ideal adsorbent for a wide variety of aromatic compounds, especially for phenols (Xu et al., 1997; Kunin 1976). Earlier SAPs are reported for the containment of wastewater to prevent it from leaving a defined containment area and reduction of the odour associated with ammonia containing wastewaters (Roach and Price 2003, 2004). The hydrophilic nature of SAPs assists in separation of water from an emulsion comprising water and lipophilic fluid. SAPs were evaluated for their use as fertilizer with the immobilization of the Olive mill wastewater (Davies et al., 2004).

Our research work is aimed at the use of SAPs for and treatment of wastewater. We have investigated the property of a starch based SAP, Jalshakt ${ }^{\circledR}$ (JS) to adsorb selectively organics from aqueous medium. This paper presents a study of the of removal of Methylene Blue by JS. The adsorption isotherms as well as kinetic parameters were also determined.

\section{MATERIALS AND METHODS}

\subsection{Materials}

The super absorbent polymer Jalshakti ${ }^{\circledR}$ (JS) used as adsorbent in this study, is a starch based SAP manufactured by Indian Organic Chemicals, Khopoli, India. It is used for agricultural purposes due to its water retaining properties, for the increase of crop production. The Methylene blue dye (MB) was purchased from E. Merck India Pvt. Ltd.

\subsection{Characterization of js}

The morphological studies of JS were done with SEM. The dried sample of JS and MB adsorbed JS was observed using SEM (JEOL - JXA 840A) microscope. The sample was coated by gold under vacuum for a few seconds, using an ion-sputtering system equipped with a magnetron electrode (Hitachi E-5100).

\subsection{Adsorption studies}

Batch adsorption experiments were performed in jar test apparatus (Phipps and Bird, USA) at room temperature i.e., $27^{\circ} \mathrm{C}$ and $\mathrm{pH} 6$ - 6.5. An agitation speed of $40 \mathrm{rpm}$ was maintained with a dose of $0.8 \mathrm{gl}^{-1}$ of JS for all the experiments. All the working solutions were prepared from the stock solution of concentration $2000 \mathrm{mg} \mathrm{l}^{-1}$ of the dye. The initial concentration of MB was varied from 100 to $1000 \mathrm{mg} \mathrm{l}^{-1}$. Aliquots of the dye solution were drawn at suitable time intervals till the equilibrium was attained. The JS was filtered and the residual dye concentration measured. All the spectral measurements were done using UV-Vis spectrophotometer (Shimadzu, Model-PC 1650). Concentrations of MB were determined by finding out the absorbance at the characteristic wavelength, $\lambda_{\max }$. The calibration curve was prepared using known concentrations and the concentration of the dye solution determined.

\subsection{Adsorption isotherm equations}

The equilibrium adsorption capacity $\mathrm{q}_{\mathrm{e}}\left(\mathrm{mgg}^{-1}\right)$ was determined as follows:

$\mathrm{q}_{\mathrm{e}}=\frac{\left(\mathrm{c}_{\mathrm{o}}-\mathrm{c}_{\mathrm{e}}\right) \mathrm{V}}{\mathrm{w}}$

$\mathrm{C}_{0}$ and $\mathrm{c}_{\mathrm{e}}$ are the initial and equilibrium concentration of MB in the solution ( $\mathrm{mg} \mathrm{l}^{-1}$ ), and $\mathrm{V}$ is the volume of the solution and $w$ is the weight of the JS.

For adsorption isotherm study, the data was analyzed employing Langmuir and Freundlich isotherm equations. The linearized Langmuir isotherm is represented by the following equation:

$$
\frac{1}{\mathrm{q}_{\mathrm{e}}}=\frac{1}{\mathrm{Q}_{0}}+\frac{1}{\mathrm{Q}_{0} \mathrm{~b}} \frac{1}{\mathrm{c}_{\mathrm{e}}}
$$


$\mathrm{Q}_{0}$ is the maximum capacity $\left(\mathrm{mg} \mathrm{g}^{-1}\right)$ and $\mathrm{b}$ is the Langmuir constant $\left(\mathrm{mg} \mathrm{l}^{-1}\right)$.

The essential characteristics of the Langmuir isotherm can be expressed in terms of a dimensionless equilibrium parameter $\left(R_{\mathrm{L}}\right)$ which can be defined by

$$
\mathrm{R}_{\mathrm{L}}=\frac{1}{1+\mathrm{bC}_{0}}
$$

The linear form of Freundlich adsorption isotherm is represented as:

$\log \mathrm{q}_{\mathrm{e}}=\log \mathrm{k}_{\mathrm{f}}+1 / \mathrm{n} \log \mathrm{c}_{\mathrm{e}}$

$\mathrm{k}_{\mathrm{f}}$ and $\mathrm{n}$ are the Freundlich constants

\subsection{Adsorption kinetics}

To investigate the kinetics of adsorption processes following three kinetic models are used: pseudo-first order model, pseudo-second order model and intraparticle diffusion model.

The Lagergren's pseudo-first order equation is:

$$
\log \left(q_{e}-q_{t}\right)=\log q_{e}-\frac{k_{1}}{2.303} t
$$

$q_{t}$ is the amount of MB adsorbed at any time 't' on JS in $\mathrm{mg} \mathrm{l}^{-1}$. A plot of log $\left(\mathrm{q}_{\mathrm{e}}-\mathrm{q}_{\mathrm{t}}\right)$ against $\mathrm{t}$ yields a straight line with $\log q_{e}$ as $y$-intercept and the rate constant $k_{1}$, which can be obtained from the slope. The regression analysis of the plot gives the correlation coefficients.

The Pseudo-second order model has the following form:

$\mathrm{t} / \mathrm{q}_{\mathrm{t}}=\frac{1}{\mathrm{k}_{2} \mathrm{q}_{\mathrm{e}}^{2}}+\frac{1}{\mathrm{q}_{\mathrm{e}}} \mathrm{t}$

The straight line plot of $t / q_{t}$ against $t$, on regression analysis yields values of $k_{2}$, the pseudo second order rate constant and $\mathrm{R}^{2}$, the regression coefficient.

The rate constant of intraparticle diffusion can be determined using the following equation:

$\mathrm{q}_{\mathrm{t}}=\mathrm{k}_{\mathrm{i}} \mathrm{t}^{0.5}+\mathrm{c}$

$\mathrm{k}_{\mathrm{i}}$ is the intraparticle diffusion rate constant in $\mathrm{mg} \mathrm{g}^{-1} \mathrm{~min}^{-1 / 2}$.

\section{RESULTS AND DISCUSSIONS}

\subsection{Characteristics of js}

Jalshakti swells into a gel approximately 50 times of its dry volume when allowed to equilibrate with water for 20-30 minutes. JS has a starch (cellulose) backbone on which $\mathrm{COOH}$ pendant groups are present along with some $-\mathrm{CH}_{2} \mathrm{OH}$ groups. The surface functionality appears to be dominated by weak acidic groups viz; - $\mathrm{COOH}$, followed by weak basic groups, viz. $-\mathrm{CH}_{2} \mathrm{OH}$. Some carboxylic acid groups exist as potassium salt i.e. $-\mathrm{COO}^{-} \mathrm{K}^{+}$. The isoelectric point (IEP) of the JS polymer is at $6.5 \mathrm{pH}$ wherein, the surface charge is neutral (Dhodapkar et al., 2006). The characteristics of JS are summarized in Table 1 (Dhodapkar et al., 2007). The pore diameter of $47 \AA$ reveals that the JS is mesoporous in nature. The structure of JS is as given below:

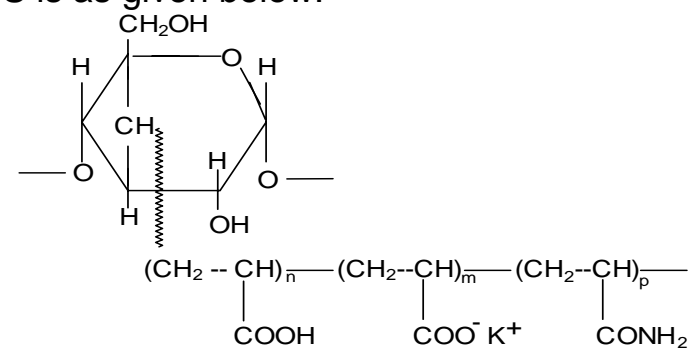

Figure 1(a) shows SEM image of the JS. Studies revealed the presence of agglomerates of polymer particles with no discrete micropores on the surface. However large intergrannular voids and crevices were found. The agglomerate size was found to be $315-350 \mu \mathrm{m}$. Figure 1(b) gives the SEM image of Methylene Blue adsorbed on the JS. It showed more porosity and intergrannular voids than JS. Agglomerates were more closely held and the size ranges were between $5-9 \mathrm{~mm}$. 
Table 1. Characteristics of JS

\begin{tabular}{lll}
\hline S.No. & Properties & Values \\
\hline 1. & Particle Size $(\mathrm{mm})$ & 0.350 \\
\hline 2. & Absorption capacity $\left(\mathrm{ml} \mathrm{g}^{-1}\right)$ & 32.14 \\
\hline 3. & True Density $\left(\mathrm{g} \mathrm{ml}^{-1}\right)$ & 1.5487 \\
\hline 4. & External Surface $\mathrm{area}^{-1}\left(\mathrm{~m}^{2} \mathrm{~g}^{-1}\right)$ & 0.2857 \\
\hline 5. & Micropore area $\left(\mathrm{m}^{2} \mathrm{~g}^{-1}\right)$ & 0.4657 \\
\hline 6. & BET Surface Area $\left(\mathrm{m}^{2} \mathrm{~g}^{-1}\right)$ & 0.7515 \\
\hline 7. & Average pore Diameter $\left(\mathrm{A}^{0}\right)$ & 47.459 \\
\hline 8. & Moisture $\%$ & $16-18$ \\
\hline 9. & Potassium $\left(\mathrm{mg} \mathrm{g}^{-1}\right)$ & 84.21 \\
\hline 10. & Volatile matter $\%$ & 6.9 \\
\hline
\end{tabular}

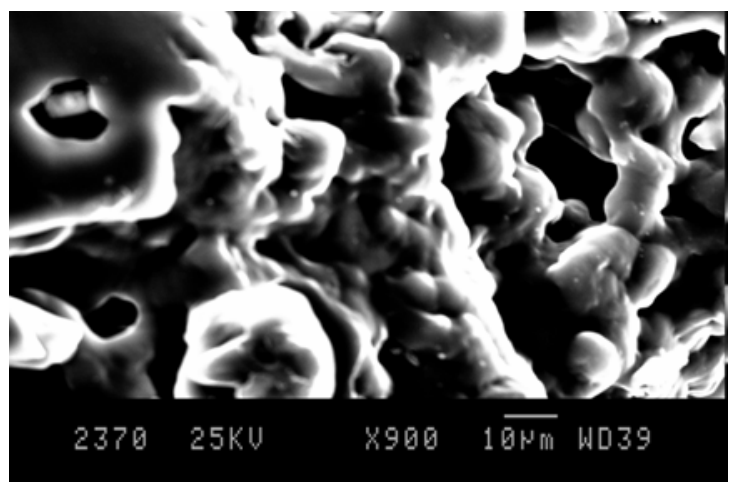

(a)

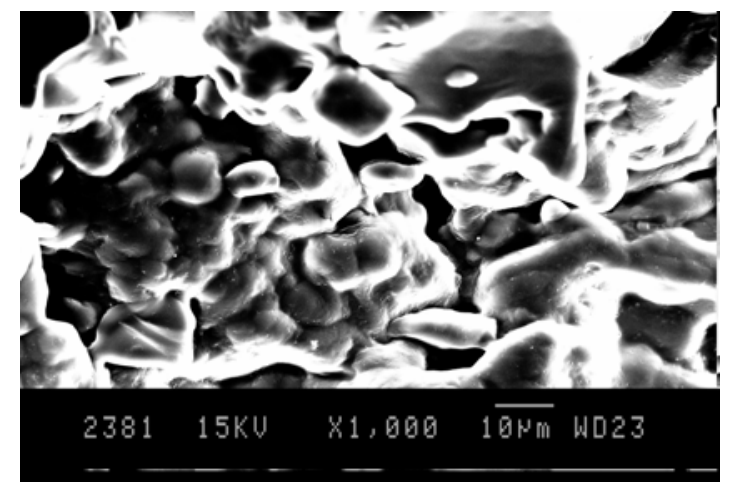

(b)

Figure 1. SEM images of (a) JS, (b) MB adsorbed JS

These interesting properties of JS fix organic pollutants viz. dyes as studied earlier which are basic in nature from their aqueous suspensions. The basic dyes adsorb strongly on JS and the appearance of the swollen polymer is a brilliant colour of the dye. The flat and planar dye molecules viz., safranine $T(S T)$, methylene blue(MB), and rhodamine B (RB) shows greater \% reductions compared to triphenylmethane(TPM) dyes viz.,crystal violet (CV), brilliant green (BG), malachilte green (MG), basic fuchsin (BF) (Figure 2). This feature can be attributed to the resistance to pore diffusion and steric hindrance exhibited by the TPM dyes because of their large molecular structure. The CV, BG, BF and MG dyes are propeller shaped molecules and are more basic also. Therefore they are adsorbed easily due to their affinity for JS. On the other hand, the flat and planar molecules viz., MB, ST and RB showed increased \% reductions as these molecules can diffuse into the pores of JS more easily (Dhodapkar et al., 2006). Moreover, Js can be regenerated by the photochemical oxidation of the adsorbed dyes and reused (Dhodapkar et al., 2007)
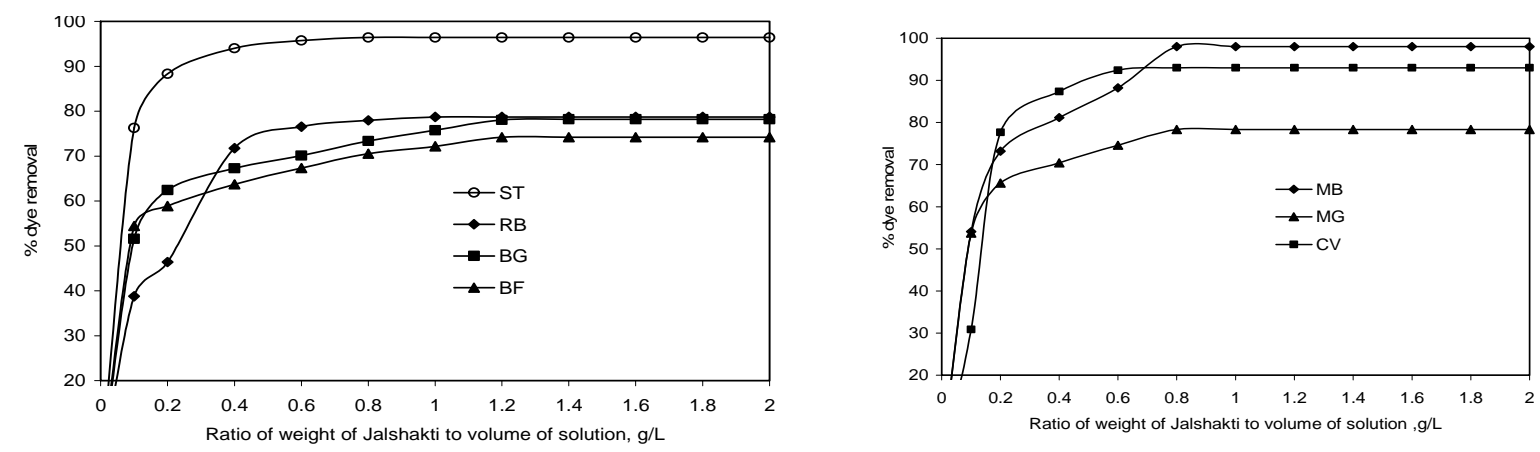

Figure 2. Percent Dye removal vs various doses of JS 
In the light of the above characteristics of JS and in view of the fact that JS is effective in removing basic dyes only, the reaction step as given in equation (8) was deduced for removal of basic dyes using JS adsorbent. The cationic dyes are attracted towards the anionic carboxylic groups.

For every mole of dye adsorbed, a mole of $\mathrm{K}^{+}$is released into medium (Dhodapkar et al., 2006). The adsorption mechanism can be likened to ion-exchange-adsorption or activated adsorption (Slokar and Le Marechal, 1997). A kinetic and isotherm study was performed for the sorption of $\mathrm{MB}$ (structure given below) on JS in batch mode<smiles>O=C([14O])c1cccs1</smiles>

(a)
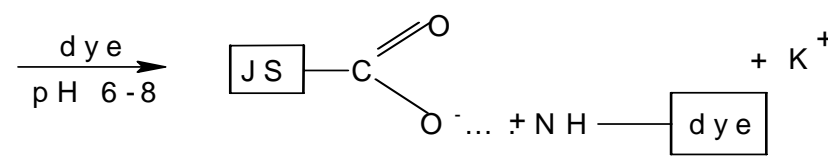

(b)

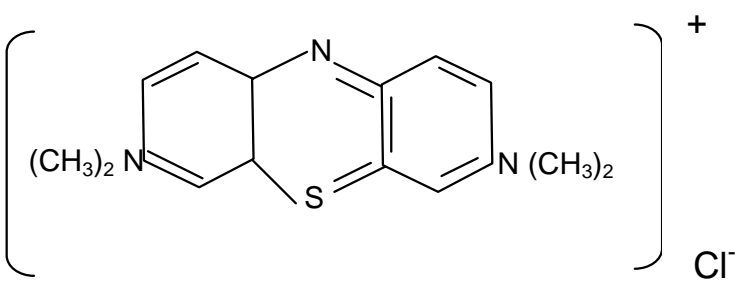

Structure of MB

\subsection{Adsorption isotherms}

Figure 3(b) presents a plot of adsorption capacity versus adsorption time at various initial MB concentrations with $0.8 \mathrm{~g} \mathrm{I}^{-1}$ of JS as determined as the optimum dose (Fig 2). The equilibrium time increases with the increasing initial dye concentration from $100 \mathrm{mg} \mathrm{l}^{-1}$ to $1000 \mathrm{mg} \mathrm{I}^{-1}$ from 55 to 140 minutes (Figure 3 (b)). The amount of MB adsorbed onto JS increases with time till it reaches a constant value. The increase in dye concentration leads to increase in sorption capacity. The equilibrium sorption capacity changes from 104 to $1094 \mathrm{mg} \mathrm{g}^{-1}$ with the increase in the initial concentration of dye from 105 to $1100 \mathrm{mg} \mathrm{l}^{-1}$ (Figure 3(a)). Rapid increase in efficiency at higher concentrations may be attributed to formation of $\mathrm{MB}$ agglomerates $\left(\mathrm{MB}^{+}\right)^{3}$ (Gurses et al., 2006) at relatively higher concentrations and its attachment to the carboxylic group of JS.

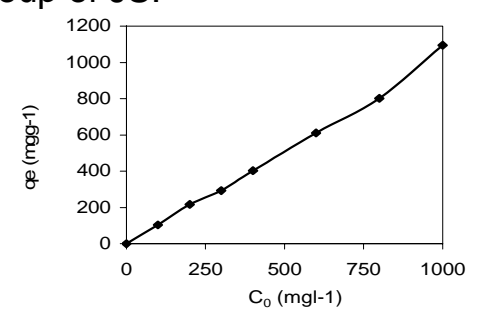

(b)

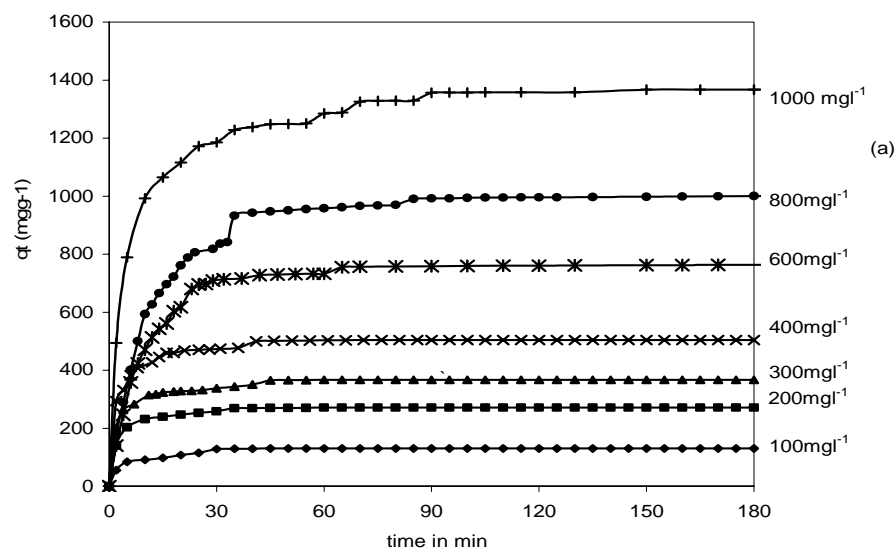

Figure 3. Effect of initial concentration of MB 
To optimize an adsorption system for the adsorption of dyes, it is important to establish the most appropriate correlation for the equilibrium curves. The equilibrium characteristics of adsorption of $\mathrm{MB}$ on JS in the present investigation were analyzed using the well known Langmuir and Freundlich isotherm equations. The Freundlich model is applied to describe heterogeneous system characterized by a heterogeneity factor of $1 / n$.

Figure $4(\mathrm{a})$ presents the linear plot of $1 / \mathrm{q}_{\mathrm{e}}$ versus $1 / \mathrm{c}_{\mathrm{e}}$ suggesting the applicability of the Langmuir model for the present system. The linear plot of $\log q_{e}$ against $\log c_{e}$ (Figure 4(b)) shows that adsorption follows Freundlich isotherm as well. The values of the Langmuir and Freundlich equation parameters are given in Table 2.

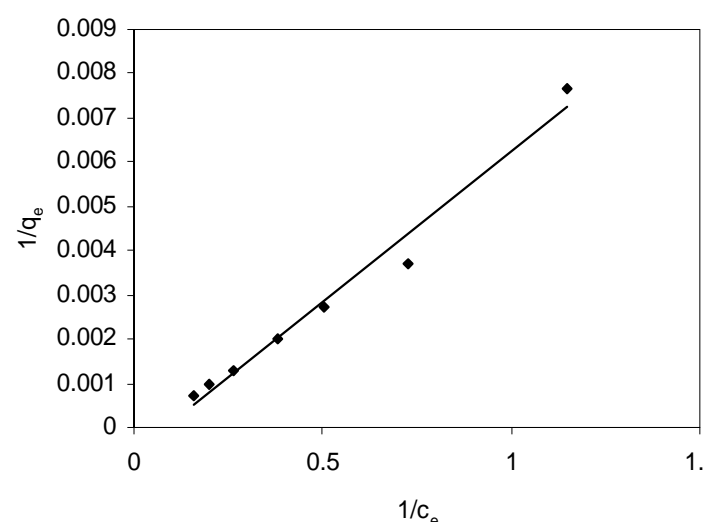

(a)

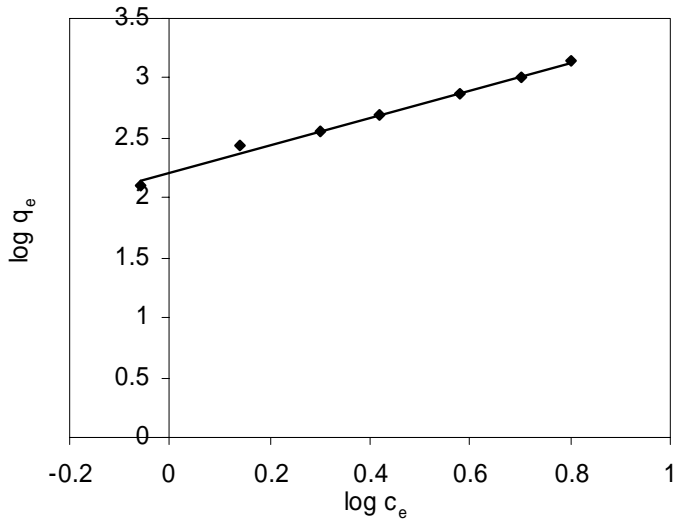

(b)

Figure 4. Langmuir (a) and Freundlich plot (b) for the adsorption of MB on JS

Table 2. Langmuir and Freundlich isotherm model constants and correlation coefficients for the adsorption of MB on JS

\begin{tabular}{lllllll}
\hline Freundlich Isotherm & \multicolumn{5}{l}{ Langmuir Isotherm } \\
\hline $\begin{array}{l}\mathrm{K}_{\mathrm{f}} \\
\left(\mathrm{mg}^{1-(1 / \mathrm{n})} \mathrm{g}^{-1} \mathrm{I}^{1 / \mathrm{n}}\right)\end{array}$ & $\mathrm{n}$ & $\mathrm{R}^{2}$ & $\begin{array}{l}\mathrm{b} \\
\left.(\mathrm{l} \mathrm{mg})^{-1}\right)\end{array}$ & $\begin{array}{l}\mathrm{Q}_{0} \\
\left(\mathrm{mg} \mathrm{g}^{-1}\right)\end{array}$ & $\mathrm{R}^{2}$ & $\mathrm{R}_{\mathrm{L}}$ \\
\hline 165.27 & 0.87 & 0.9937 & 0.0735 & 1200 & 0.9786 & 0.0134 \\
\hline
\end{tabular}

Adsorption conditions: initial concentration-100-1000 mg l-1, $\mathrm{pH}-6-6.5$, JS content- $0.8 \mathrm{~g} \mathrm{l}^{-1}$ agitation speed-40 rpm.

The equilibrium parameter, $R_{L}$ was found to be 0.0134 which confirmed that the Langmuir model is favourable (Tan et al., 2007). However, the correlation coefficient for the Freundlich isotherm is higher than that for Langmuir, suggesting higher probability of multilayer adsorption than monolayer adsorption. High adsorption capacity indicates the strong electrostatic force of attraction between dye molecules and sorbent binding sites. The $K_{f}$ value is $165.3 \mathrm{mg}^{1-(1 / \mathrm{n})} \mathrm{g}^{-1} \mathrm{~L}^{1 / \mathrm{n}}$. The slope $1 / \mathrm{n}$, ranging between 0 and 1 , is indicative of the relative energy distribution on the adsorbent surface (or surface heterogeneity) (Al-Ghouti et al., 2003). In the initial process MB adsorbs on the external surface of the particles of JS leading to increase in local concentration of dye and formation of aggregates of MB as reported by Gurses et al. (2006) for MB-clay interaction. This is followed by internal diffusion of dye particle into internal sites. The greatest extent of agglomeration occurs at high dye loadings, while monomers and protonated cations predominate at low concentrations.

Table 3 presents a detailed account of the maximum adsorption capacities of MB for various adsorbents as reported in the literature along with the adsorbent used in this study. The adsorption capacity of the JS is much higher than other adsorbents investigated probably because of its mesoporous nature.

\subsection{ADSORPTION KINETICS}

The three kinetic models tested are based on pseudo first order, pseudo second order and intraparticle diffusion processes. The results of fitting the experimental data with pseudo-first order, pseudo-second order equations and intraparticle diffusion models are given in Table 4. 
Table 3. Materials used as adsorbent for Methylene blue

\begin{tabular}{|c|c|c|}
\hline Adsorbent & $\begin{array}{l}\text { Capacity } \\
\left(\mathrm{mg} \mathrm{g}^{-1}\right)\end{array}$ & Reference \\
\hline$A C$ & 63.8 & Dhodapkar et al., 2006 \\
\hline Bentonite & 150 & Mckay and Poots,1986 \\
\hline Activated date pits $\left(500^{\circ} \mathrm{C}\right)$ & 12.9 & Banat et al., 2003 \\
\hline Activated date pits $\left(900^{\circ} \mathrm{C}\right)$ & 17.3 & Banat et al., 2003 \\
\hline Activated furniture $\left(850^{\circ} \mathrm{C}\right)$ & 200.0 & Sainz-Diaz and Griffiths, 2000 \\
\hline $\begin{array}{l}\text { Activated olive stones with } 40 \\
\text { wt. } \% \mathrm{ZnCl}_{2} \text { at } 873 \mathrm{~K}\end{array}$ & 16.1 & Alaya et al., 1999 \\
\hline $\begin{array}{l}\text { Activated olive stones with } 40 \\
\text { wt. } \% \mathrm{ZnCl}_{2} \text { at } 873 \mathrm{~K} \text { in nitrogen } \\
\text { atmosphere }\end{array}$ & 22.1 & Alaya et al., 1999 \\
\hline Activated sewage char $\left(800^{\circ} \mathrm{C}\right)$ & 120 & Sainz-Diaz and Griffiths, 2000 \\
\hline Activated tyres $\left(850^{\circ} \mathrm{C}\right)$ & 130 & Sainz-Diaz and Griffiths, 2000 \\
\hline Activated tyre char & 227.0 & Lin and Teng , 2002 \\
\hline Amorphous silica & 26.5 & Woolard et al., 2002 \\
\hline Banana peel & 20.8 & Annadurai et al., 2002 \\
\hline Calcined pure kaolin & 8.88 & Ghosh and Bhattacharya, 2002 \\
\hline Chrome sludge & 0.51 & Lee et al., 1996 \\
\hline Clay & 58.2 & Gurses, et al., 2006 \\
\hline Cotton waste & 24 & Mckay and Poots,1986 \\
\hline Cedar saw dust & 92.78 & Hamdaoui, 2006 \\
\hline Crushed brick & 44.93 & Hamdaoui, 2006 \\
\hline Fly ash & 1.3 & Woolard et al., 2002 \\
\hline JS & 1200 & Present work \\
\hline $\mathrm{NaOH}$ treated pure kaolin & 20.49 & Ghosh and Bhattacharya, 2002 \\
\hline Orange peel & 18.6 & Annadurai et al., 2002 \\
\hline Pure kaolin & 15.55 & Ghosh and Bhattacharya , 2002 \\
\hline Pyrolysed furniture & 80 & Sainz-Diaz and Griffiths, 2000 \\
\hline Raw date pits & 80.3 & Banat et al., 2003 \\
\hline Wood & 84 & Mckay and Poots, 1986 \\
\hline Zeolite & 12.7 & Woolard et al., 2002 \\
\hline
\end{tabular}

\section{Pseudo-first order model}

Lagergren's kinetics equation describes the adsorption of liquid- solid systems based on solid capacity. In order to distinguish kinetic equations based on concentration of solution and adsorption capacity of a solid, Lagergren's first order rate equation has been called pseudofirst order (Ho, 2004).

It can be observed from Table 4, that the correlation coefficients for first order model vary between 0.924 and 0.971 and most of the first order $q_{e}$ values deviate significantly from the experimental values. The intercept of the straight line plots of $\log \left(\mathrm{q}_{\mathrm{e}}-\mathrm{q}_{\mathrm{t}}\right)$ against $t$, are not equal to or reasonably close to $\log q_{\mathrm{e}}$. This indicates that the adsorption is not likely to be first order (Gurses et al., 2006; Ho and McKay, 1998).

According to most studied adsorption systems, the first order equation of Lagergren does not fit well over the entire adsorption period and is generally applicable for the rapid initial phase. The high values of $R^{2}$ adequately describe the first portion of adsorption (Hamdaoui, 2006). 
Table 4. Comparison of the pseudo first order, pseudo second order and intraparticle diffusion models for different initial MB concentrations

\begin{tabular}{|c|c|c|c|c|c|c|c|c|c|c|}
\hline \multirow{2}{*}{$\begin{array}{l}\text { Initial MB } \\
\text { concen- } \\
\text { tration } \\
\left(\mathrm{mg} \mathrm{l}^{-1}\right)\end{array}$} & \multirow{2}{*}{$\begin{array}{l}\mathrm{q}_{\mathrm{e}, \exp } \\
\left(\mathrm{mg} \mathrm{g}^{-1}\right)\end{array}$} & \multicolumn{3}{|c|}{ Pseudo-First order } & \multicolumn{3}{|c|}{ Pseudo-second order } & \multicolumn{3}{|c|}{ Intraparticle diffusion } \\
\hline & & $\begin{array}{l}\mathrm{q}_{\mathrm{e} 1, \mathrm{cal}} \\
\left(\mathrm{mg} \mathrm{g}^{-1}\right)\end{array}$ & $\mathrm{R}_{1}^{2}$ & $\begin{array}{l}\mathrm{k}_{1} \\
\left(10^{-3}\right. \\
\left.\min ^{-1}\right)\end{array}$ & $\begin{array}{l}\mathrm{q}_{\mathrm{e} 2, \mathrm{cal}} \\
\left(\mathrm{mg} \mathrm{g}^{-1}\right)\end{array}$ & $\mathrm{R}_{2}^{2}$ & $\begin{array}{l}\mathrm{k}_{2} \\
\left(10^{-3} \mathrm{~g} \mathrm{mg}^{-1}\right. \\
\left.\mathrm{min}^{-1}\right)\end{array}$ & $\begin{array}{l}\mathrm{k}_{\mathrm{i}} \\
\left(\mathrm{mg} \mathrm{g}^{-1}\right. \\
\left.\mathrm{min}^{-1 / 2}\right)\end{array}$ & $\mathrm{R}_{\mathrm{i}}^{2}$ & C \\
\hline 105 & 130 & 152.26 & 0.9524 & 134.7 & 139 & 0.9936 & 2.02 & 11.21 & 0.9742 & 56.91 \\
\hline 215 & 270 & 203.38 & 0.9682 & 122.7 & 278 & 0.9991 & 2.02 & 19.02 & 0.9401 & 164.47 \\
\hline 295 & 366 & 268.16 & 0.9244 & 102 & 370 & 0.9984 & 1.18 & 35.19 & 0.9779 & 192.56 \\
\hline 405 & 503 & 285.96 & 0.9667 & 94.6 & 526 & 0.9995 & 0.95 & 58.42 & 0.9523 & 228.73 \\
\hline 614 & 763 & 317.91 & 0.9477 & 42.4 & 769 & 0.9992 & 0.29 & 121.97 & 0.9894 & 83.761 \\
\hline 806 & 1002 & 442.49 & 0.9478 & 33.9 & 1000 & 0.9990 & 0.16 & 98.34 & 0.9578 & 299.86 \\
\hline 1100 & 1367 & 902.82 & 0.9710 & 43.8 & 1428 & 0.9997 & 0.16 & 84.16 & 0.9868 & 735.24 \\
\hline
\end{tabular}

Adsorption conditions: initial concentrations: $100-1000 \mathrm{mg} \mathrm{l}^{-1}$, JS content: $0.8 \mathrm{~g} \mathrm{I}^{-1}$ and agitation speed: $40 \mathrm{rpm}$.

\section{Pseudo-second order model}

The pseudo-second order rate expression is based on the sorption capacity of solids but contrary to previous model it describes chemisorption over the whole adsorption time (McKay and Ho, 1999). The adsorption rate equations have considered the adsorption capacities of solids since Lagergren's first order equation was presented. The advantage with this model is that, there is no need to know the equilibrium capacity from the experiments, as it can be calculated from the model (Ho, 2006).

The calculated kinetic parameters for the model are given in Table 4. The correlation coefficients are greater than 0.99 reflecting a compatible relation with experimental data. The experimental $\mathrm{q}_{\mathrm{e}}$ values are closer to the calculated ones. Further, there was very minor deviation between expected and observed $\mathrm{q}_{\mathrm{e} 2}$ (amount of dye adsorbed at equilibrium, $\mathrm{mg} / \mathrm{g}$ ) values. It can be said that more than one-step may be involved in sorption process.

Thus, it can be inferred that the equilibrium sorption capacities for pseudo-second order model are much more reasonable when compared with experimental results than that of the pseudo-first order model. The calculated correlation coefficients are also closer to unity. Therefore, the sorption process can be approximated more favourably by the pseudo-second order kinetic model, suggesting the sorption process to be a chemisorption process involving exchange or sharing of electrons mainly between dye cations and functional groups of JS (Chandra et al., 2007; Namasivayam and Kavitha, 2002).

The equilibrium sorption capacity, $\mathrm{q}_{\mathrm{e} 2}$, increased from 139 to $1428 \mathrm{mg} \mathrm{g}^{-1}$ when the initial concentration of dye increased from 105 to $1100 \mathrm{mg} \mathrm{l}^{-1}$ (Table 4), indicating that the dye removal is dependent on initial concentration. While the initial concentration varies from 105 to $1100 \mathrm{mg} \mathrm{l}^{-1}$, the rate constant, $\mathrm{k}_{2}$, decrease from 2.02 to 0.16 .

\subsection{INTRAPARTICLE DIFFUSION MODEL}

The sorption kinetic data were further processed to determine whether intraparticle diffusion is rate limiting and to find rate parameter for intraparticle diffusion $\left(\mathrm{k}_{\mathrm{i}}\right)$. Figure 5 presents a plot of $\mathrm{q}_{\mathrm{t}}$ versus $\mathrm{t}^{0.5}$ at different initial dye concentrations. This model has been applied to gain a deeper knowledge about the mechanism of dye sorption onto JS. 


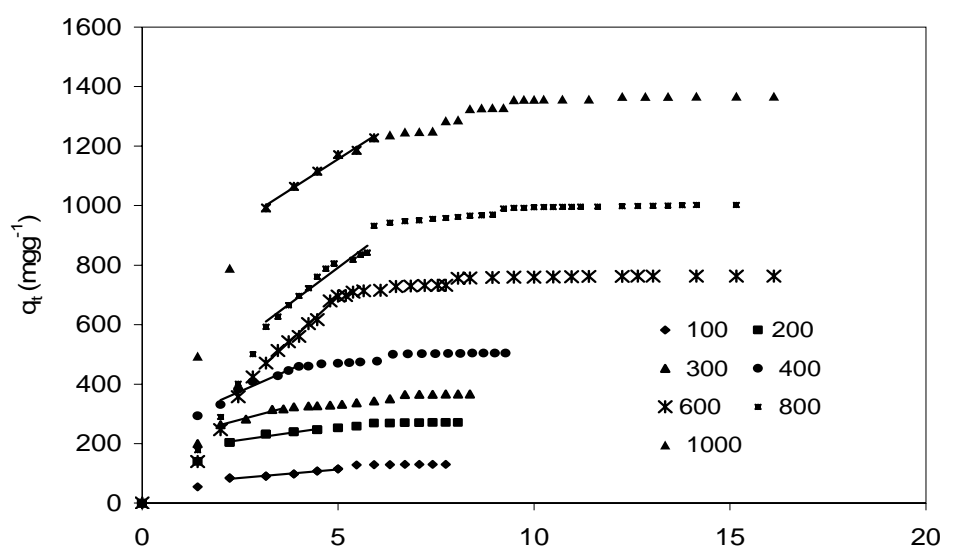

Figure 5. lots of intraparticle diffusion model for different initial concentrations of $\mathrm{MB}, \mathrm{mg} \mathrm{g}^{-1}$

The values of constants, ki and c, and the correlation coefficients are given in Table 4. These plots have generally the multilinear nature and can be explained in terms of few processes. The boundary layer diffusion gives the initial part of the plot, the gradual adsorption stage represents the rate limiting intraparticle diffusion, followed by the equilibrium stage where the intraparticle diffusion starts to slow down due to extremely low adsorbate concentration left in the solution (Sun and Wang 2003; Tseng et al., 2003). The plots reveal a linear characteristic at a certain time limit but do not pass through the origin. If particle diffusion is the rate controlling step then the line should pass through the origin. The intercept (c) is obtained by extrapolating the linear portion of the plot back to the $y$-axis, and is proportional to the extent of boundary layer thickness. This also indicates that intraparticle diffusion is involved in the sorption process but not the only rate-limiting mechanism (Gurses et al., 2006; Hamdaoui 2006).

On comparing, the correlation coefficients, they were found to be lower than the values obtained for second order model. This suggests that the pseudo-second order sorption mechanism is predominant. However, it also implies that the adsorption process to be controlled by both diffusion of dye cations and extent of interactions between dye cations and binding sites on the JS.

\section{CONCLUSIONS}

JS used in this study is mesoporous in nature with a water absorption capacity of $32.14 \mathrm{ml} \mathrm{g}^{-1}$. It is a potential adsorbent for removal of basic dyes from aqueous solutions over a wide range of concentrations. Its unique swelling property facilitates adsorption of these dyes. Basicity, molecular size and stereochemistry of the dyes appear to influence adsorption over JS. The basic dyes are removed through adsorption-exchange mechanism involving carboxylic acid groups and potassium ions of JS.

The equilibrium adsorption capacity increases from 138.9 to $1428.6 \mathrm{mg} \mathrm{g}^{-1}$ as the initial concentration of MB increases from $100-1100 \mathrm{mg} \mathrm{l}^{-1}$. The experimental equilibrium data was fitted to the Langmuir and Freundlich adsorption isotherm models to test the fitness of these equations. The equilibrium parameter, $R_{L}$ was found to be 0.0134 which confirmed that the Langmuir model is favourable. The maximum adsorption capacity obtained is $1200 \mathrm{mg} \mathrm{g}^{-1}$ which is more than the adsorbents reported in literature. High adsorption capacity indicates the strong electrostatic force of attraction between dye molecules and sorbent binding sites. The $K_{f}$ value is $165.3 \mathrm{mg}^{1-(1 / \mathrm{n})} \mathrm{g}^{-1} \mathrm{I}^{1 / n}$. The slope $1 / \mathrm{n}$, ranging between 0 and 1 , is indicative of the relative energy distribution on the adsorbent surface (or surface heterogeneity). The kinetics of the adsorption process suggests that the pseudo second order model is predominant. The pore diffusion kinetics as described by intraparticle diffusion model also controls the adsorption process but is not the only rate limiting mechanism. 


\section{REFERENCES}

Abraham J. and Pillai V.N.R., (1996), Membrane-encapsulated controlled-release urea fertilizers based on acrylamide copolymers, Journal of Applied Polymer Science, 60, 2347-2351.

Alaya M., Hourieh M., Youssef A. and El-Sejarah F., (1999), Adsorption properties of activated carbons prepared from olive stones by chemical and physical activation, Adsorption Science Technology, 18, 27-42.

Al-Ghouti M.A., Khraisheh M.A.A., Allen S.J. and Ahmad M.N., (2003), The removal of dyes from textile wastewater: a study of the physical characteristics and adsorption mechanisms of diatomaceous earth. Journal of Environment Management, 69, 229- 238

Annadurai G., Juang R. and Lee D., (2002), Use of cellulose-based wastes for adsorption of dyes from aqueous solutions, Journal of Hazardous Materials, 92, 263-274.

Badiger M.V., Kulkami M.G. and Mashelkar R.A., (1992), Concentration of macromolecules from aqueous solutions:a new swellex process, Chemical Engineering Science, 47, 3-9.

Banat F., Al-Asheh S. and Al-Makhadmeh L., (2003), Evaluation of the use of raw and activated date pits as potential adsorbents for dye containing waters, Process Biochemistry, 39, 193202.

Bastioli C. (1995) Starch-polymer composites, In: Degradable polymers, Scott G. and Gilead D. (Eds) Chapman \& Hall, London.

Buchholz F.L. and Graham A.T. (1997) Modern superabsorbent polymer technology, Wiley, New York.

Chandra T.C., Mirna M.M., Sudaryanto Y. and Ismadji S., (2007), Adsorption of basic dye onto activated carbon prepared from durian shell: Studies of adsorption equilibrium and kinetics, Chemical Engineering Journal, 127, 121-129.

Cussler E.L., Stokar M.R. and Varberg J.E., (1984), Gels as size selective extraction solvents. American Institute of Chemical Engineers, I 30, 578-582.

Davies L.C., Novais J.M. and Martins-Dias S., (2004), Influence of salts and phenolic compounds on olive mill wastewater detoxification using superabsorbent polymers, Bioresource Technology, 95, 259-268.

Dhodapkar R., Rao, N.N., Pande S.P. and Kaul S.N., (2006), Removal of basic dyes from aqueous medium using a novel polymer-Jalshakti, Bioresource Technology, 97, 877-885.

Dhodapkar R., Rao N.N., Pande S.P., Nandy T. and Devotta S., (2007), Adsorption of cationic dyes on super absorbent polymer and photocatalytic regeneration of the adsorbent, Reactive and Functional Polymers, 67 ,540-548.

Du J.J., (2002), Research on preparation of water-absorbent controlled release fertilizer and evaluation method to controlled release fertilizer, Ph D dissertation, South China Agricultural University.

Freitas R.F.S. and Cussler E.L., (1987), Temperature sensitive gels as extraction solvents, Chemical Engineering Science, 42, 97-103.

Gehrke S.H., Andrews G.P. and Cussler E.L., (1986), Chemical aspects of gel extraction, Chemical Engineering Science, 41, 2153-2160.

Ghosh D. Bhattacharya K.G., (2002), Adsorption of methylene blue on kaolinite, Applied Clay Science, 20, 295-300.

Grifin G.J.L. (ed.) (1994), Chemistry and technology of biodegradable polymers, Blackie Academic \& Professional, London.

Guo M.Y., Liu M.Z., Hu Z., Zhan F.L. and Wu L., (2005), Preparation and properties of a slow release NP compound fertilizer with superabsorbent and moisture preservation, Journal of Applied Polymer Science, 96, 2132-2138.

Gurses C., Dogar M., Yalcin M., Acikyildiz R., Bayrak and karaca S., (2006), Adsorption kinetics of the cationic dye, methylene blue, onto clay, Journal of Hazardous Materials B, 131, 217-228.

Hamdaoui O., (2006), Batch study of liquid-phase adsorption of methylene blue using cedar sawdust and crushed brick, Journal of Hazardous Materials, 135, 264-273.

He X.S. and Zhang F.D., (2005), Characteristics and performance of water-absorbent polymer coated urea fertilizer, Plant Nutrition and Fertilizer Science, 11, 334-339.

He X.S., Liao Z.W., Huang P.Z., Duan J.X., Ge R.S., Li H P. and Zhao J.H., (2006), Research advances in slow controlled-release water storing fertilizers, Transactions of Chinese Society of Agricultural Engineering, 22, 184-190. 
Ho Y.S., (2004), Citation review of Lagergren kinetic rate equation on adsorption reactions, Scientometrics, 59, 171-177.

Ho Y.S., (2006), Review of second-order models for adsorption systems, Journal of Hazardous Materials B, 136, 681-689.

Ho Y.S. and McKay G., (1998), Sorption of dye from aqueous solution by peat, Chemical Engineering Journal, 70, 115-124.

Karadag E., Saraydin D., Caldiran Y. and Gueven O., (2000), Swelling studies of copolymeric acrylamide/crotonic acid hydrogels as carriers for agricultural uses, Polymer Advance Technology, 11, 59-68.

Kunin R., (1976), The use of macroreticular polymeric adsorbents for the treatment of waste effluents, Pure Applied Chemistry, 46, 205-211.

Lee C., Low, K. and Chow S., (1996), Chrome sludge as an adsorbent for color removal, Environment Technology, 17, 1023-1028.

Lenzi F., Sannino A., Borriello A., Porro F., Capitani D. and Mensitieri G., (2003), Probing the degree of crosslinking of a cellulose based superabsorbing hydrogel through traditional and NMR techniques, Polymer, 44, 1577-1588.

Li Y.L., (2003), Study on synthesis of microelement water-retaining reagent of soil, Journal of Chemistry industry, 17, 21-23.

Lin Y., Teng H., (2002), Mesoporous carbons from waste tire char and their application in wastewater discoloration, Microporous Mesoporous Materials, 54, 167-174.

Mahdavinia G.R., Pourjavadi A., Hosseinzadeh H. and Zohuriaan M.J., (2004), Modified chitosan 4 Superabsorbent hydrogels from poly(acrylic acid-co-acrylamide) grafted chitosan with salt- and pH-responsiveness properties, European Polymer Journal, 40,1399-1407.

McKay G., Ho, Y.S., (1999), Pseudo-second-order model for sorption processes, Process Biochemistry, 34, 451-465.

Mckay G. and Poots V.J., (1986), Kinetics and diffusion processes in colour removal from effluent using wood, Chemical Technology Biotechnology, 30, 279-282.

Mikkelsen R.L., (1994), Use hydrophilic polymers to control nutrient release, Fertilizer Research, 38, 53-59.

Mikkelsen R.L., (1995), Use hydrophilic polymers to improve uptake of manganese fertilizers by soyabeans, Fertilizer Research, 41, 87-92.

Namasivayam C. and Kavitha D., (2002), Removal of Congo Red from water by adsorption onto activated carbon prepared from coir pith, an agricultural solid waste, Dyes Pigments, 54, 4748.

Pill W.G. and Watts D.M., (1983), Nutrient-fortified gel as a growth medium for tomato seedlings, Horticultural Science, 18, 909-911.

Roach G.W. and Price E.G., (2004), Wastewater containment and treatment methods, US Patent Applic. 200400007534.

Roach G.W. and Price E.G. (2003) Wastewater containment and treatment methods and apparatus, U.S. Patent 6,623,645.

Sainz-Diaz C. and Griffiths A., (2000), Activated carbon from solid wastes using a pilot-scale batch flaming pyrolyser, Fuel, 79, 1863-1871.

Scott G. and Gilead D. (Eds.) (1995). Degradable polymers, Chapman \& Hall, London.

Slokar Y.M. and Le Marechal A.M., (1997), Methods of decolouration of textile wastewaters. Dyes Pigments, 37, 335-356.

Smith J.D. and Harrison H.C., (1991), Evaluation of polymers for controlled release properties when incorporated with nitrogen fertilizer solutions, Communications in Soil Science and Plant Analysis, 22, 559-573.

Sun Q. and Yang L., (2003), The adsorption of basic dyes from aqueous solution on modified peat-resin particle, Water Research, 37, 1535-1544.

Tan I.A.W., Hameed B.H. and Ahmad A.L., (2007), Equilibrium and kinetic studies on basic dye adsorption by oil palm fibre activated carbon, Chemical Engineering Journal, 127, 111-119.

Tseng R.L., Wu F Ch. and Juang R.S., (2003), Liquid- phase adsorption of dyes and phenols using pinewood-based activated carbons, Carbon, 41, 487-495.

Vasheghani-Farahani E., Cooper D.G., Vera J.H. and Weber M.E., (1992), Concentration of large biomolecules with hydrogels, Chemical Engineering Science, 47, 31-40. 
Wang L.L., Wen G.H., Tana-Zhang L., Li S.M. and Tian W.P., (2005), Synthesis and properties of super absorbent polymer contained potassium and nitrogen, Chinese Journal of Colloid and Polymer, 23, 32-42.

Woolard C., Strong J. and Erasmus C., (2002), Evaluation of the use of modified coal ash as a potential sorbent for organic waste streams, Applied Geochemistry, 17, 1159-1164.

Xu S., Wang J., Wu R., Wang J. and Li H., (2006), Adsorption behaviours of acid and basic dyes on crosslinked amphoteric starch, Chemical Engineering Journal, 117, 161-167.

Xu Z.Y., Zhang Q.X., Wu C.L. and Wang L.S., (1997), Adsorption of naphthalene derivatives on different macroporous polymeric adsorbents, Chemosphere, 35, 2269-2276.

Ye Y., Cui Y D., Yin G.Q., Kang Z. and Liao L.W., (2000), Production and use of water-absorbent long-effect compound fertilizer, Guangzhou Chemistry Industry, 28, 91-93,78.

Zhan F.L., Liu M.Z., Guo M.Y. and Wu L., (2004), Preparation of superabsorbent polymer with slow-release phosphate fertilizer, Journal of Applied Polymer Science, 92, 3417-3421.

Zhou B., (2003), Production and uses of water-absorbent long effect compound fertilizer, Journal of the Chemical Fertilizer Industry, 30, 55-56. 